\title{
Retour sur « Le Chasseur et son fusil en Haute- Provence »
}

Frédéric Joulian

\section{(2) OpenEdition \\ 12 Journals}

Édition électronique

URL : https://journals.openedition.org/tc/5078

DOI : $10.4000 /$ tc. 5078

ISSN : 1952-420X

Éditeur

Éditions de l'EHESS

\section{Édition imprimée}

Date de publication : 30 juin 2010

Pagination : 506-508

ISSN : 0248-6016

\section{Référence électronique}

Frédéric Joulian, «Retour sur « Le Chasseur et son fusil en Haute-Provence » », Techniques \& Culture [En ligne], 54-55 | 2010, mis en ligne le 30 juin 2013, consulté le 29 septembre 2022. URL : http:// journals.openedition.org/tc/5078; DOI : https://doi.org/10.4000/tc.5078 


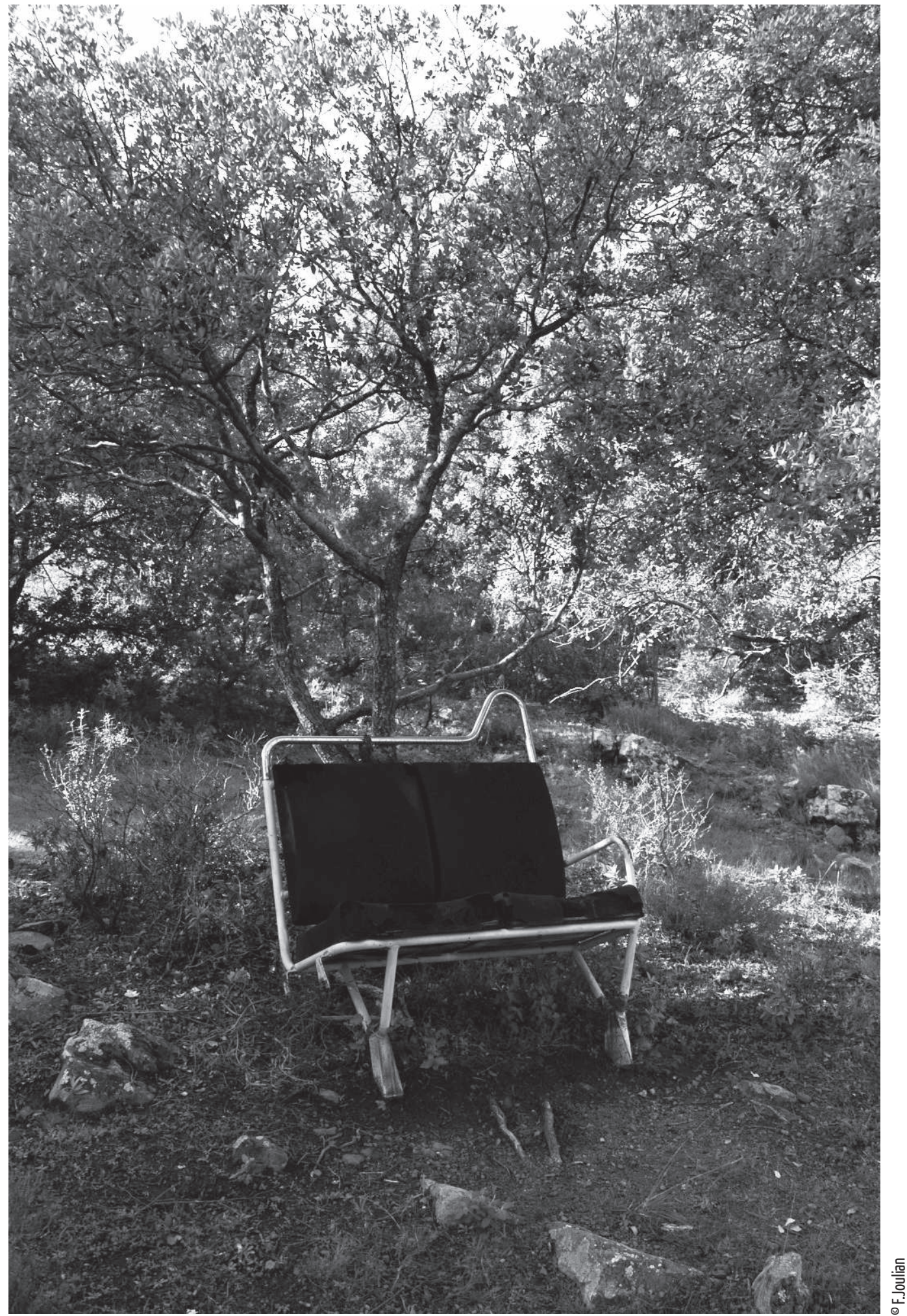




\section{Retour sur}

\section{"Le Chasseur et son fusil en Haute-Provence »}

Nicolas Govoroff nous a quittés le 11 février dernier alors que nous achevions l'introduction de cette anthologie. Avec Gil Bartholeyns et les autres membres de Techniques \& Culture, il nous a semblé important de la compléter d'un de ses textes. Malheureusement, s'il avait depuis longtemps généreusement travaillé à la revue, il n’y avait jamais publié. Le texte que nous avons choisi, paru en anglais, est extrait de l'ouvrage Technological choices. Transformation in material cultures since the Neolithic dirigé par Pierre Lemonnier (1993) qui s'était alors efforcé de réunir les principaux acteurs de la technologie culturelle, de la sociologie de l'innovation et de l'anthropologie des techniques (Joulian 1995). Ce texte s'est naturellement imposé tant il illustre l'intrication des aspects techniques, économiques et symboliques que Nicolas abordait empiriquement et avec élégance et une rare économie de moyens.

« Le Chasseur et son fusil en Haute-Provence » est une sorte de concentré du travail que Nicolas Govoroff réalisait dans la région du Haut-Verdon depuis ses débuts d'ethnologue. Il poussait également ses investigations jusqu'au littoral varois dans le cadre d'autres travaux, sur la transhumance ou l'abattage du gibier par exemple. Nous avons pensé que cet article - hormis ses recherches au long cours sur la pêche à la lamproieétait le meilleur moyen de faire connaître son approche de la culture matérielle.

Formé à l'ethnologie générale à Nanterre mais constamment en dialogue avec différents acteurs de la technologie culturelle, Nicolas Govoroff n'était pas l'homme d'une école, d'un courant; il savait en outre se démarquer des approches dominantes en produisant une connaissance tout à la fois détaillée et intégrée. Nicolas était un ethnologue «tout terrain », « multifocal » et d'une rare sensibilité: de l'ethnographie détaillée des instruments de capture ou de mise à mort aux perspectives générales sur les classes d'âge ou la différenciation sexuelle des activités ou sur l'échange (Testart et al. 2003), il traversait bon nombre des grands thèmes de l'anthropologie. 
La photo du « poste à grives » de l'ouverture illustre l'espère, le hors-lieu, le hors-temps, le hors-loi, la socialité masculine, le bricolage. Comme les cartouches abandonnées, ce fauteuil vide « tombé d'un bus» évoque la marque de l'individu dans l'espace naturel.

Carnoules, Massif des Maures, 2005
Dans cet article, il restitue et subsume, en quelques pages, un corpus immense de thèmes, récits, expériences pratiques, et bien sûr, de chaînes opératoires qui lui permettaient d'avancer discrètement, mais sûrement, différentes interprétations sur les rapports aux animaux, à la nature ou aux hommes. Ses très grandes connaissances en matière de chasse, de pêche ou d'élevage se fondaient sur la littérature scientifique mais également sur un savoir-faire de spécialiste. Un ethnologue qui ne ferait qu'observer sans également pratiquer manquerait à coup sûr bien des éléments découverts et exposés dans cet article. Nicolas Govoroff était de ceux qui n'hésitent pas à s'immerger et participer pour comprendre. En ce sens, cet article et sa démarche n'ont pas pris une ride et peuvent servir de modèle au lecteur d'aujourd'hui ou de demain.

Plus récemment, en 2002, nous avions travaillé ensemble en Afrique de l'Ouest chez les chasseurs Koulango de la Côte d'Ivoire (Govoroff s/p) et au Ghana, en 2007, dans les forêts du sud du pays dans le cadre d'un projet sur le « Dahomey-gap » (Govoroff 2007). Quelques photos en fin d'article illustrent notre terrain croisé et le regard tout à la fois empathique et critique de Nicolas. Ces images tentent aussi de faire le lien, sur la base d'une communauté universelle de pratiques, celle des chasseurs, entre deux aires culturelles fort éloignées. Mais c'est là une autre histoire, encore à écrire.

\section{NDLR}

La revue remercie Pierre Lemonnier et les éditions Taylor and Francis Books (London \& New York : Routledge) de nous avoir autorisé à traduire et éditer cet article de Nicolas Govoroff paru dans sa version originale en anglais en 1993, sous le titre The hunter and his gun in Haute-Provence. 